\title{
Breast Adenomyoepithelioma
}

National Cancer Institute

\section{Source}

National Cancer Institute. Breast Adenomyoepithelioma. NCI Thesaurus. Code C6899.

A usually benign tumor arising from the breast. It is characterized by the proliferation of cells with myoepithelial differentiation around spaces which are lined by epithelial cells. Rarely, the epithelial and/or myoepithelial cells may undergo malignant transformation. Cases with malignant transformation may follow an aggressive clinical course, including recurrences and local and distant metastases. 